\title{
Synaptic Competitive-Learning Therapy for Spinal Cord Injury
}

Venkata Krishnan $\mathbf{R}^{*}$

Retired Head, Department of Anatomy, Fiji School of Medicine Suva, Fiji Islands (South Pacific)

*Corresponding author: Venkata Krishnan R, Retired Head, Department of Anatomy, Fiji School of Medicine Suva, Fiji Islands (South Pacific), Tel: 25399422; E-mail: krish_venk@yahoo.com

Rec date: June 16, 2014, Acc date: Jun 20, 2014, Pub date: Jun 23, 2014

Copyright: (C) 2014 Krishnan VR. This is an open-access article distributed under the terms of the Creative Commons Attribution License, which permits unrestricted use, distribution, and reproduction in any medium, provided the original author and source are credited.

\section{Letter to Editor}

This letter refers to my paper published (JND 1:134, Sept, 26, 2013) titled: Restoring Motor Functions in Spinal cord Injury, Hemiplegic Cerebral Palsy, and Stroke by Botulinum toxin-induced Synaptic Completive-learning Therapy. The paper has already received tremendous online readerships and is growing. I now invite your readers to please visit the YouTube websites in which I have recently posted video clips of spinal cord compete injury (SCIc) paraplegic amphibian animal model to show that synaptic competitive-learning (SCL) therapy brings remarkable and long lasting locomotor recovery. Indeed the roots of the present findings go back to discoveries in the early 1980s that surgically/drug-induced synapse-competition among neuromuscular synapses concurrently generates complementary plasticity and circuit modification effects at spinal cord and cerebral cortical neuronal levels. I believe that the videos will stimulate even greater interest among your readers, convince and encourage them to embark on future studies on higher mammalian species and translate their findings to clinical trials in SCI paralytics.

A New Surgical/ Therapeutic Treatment Model for Spinal cord Injured - Video 1

\begin{abstract}
http://www.youtube.com/watch?v=6xwMGm_8C78
\end{abstract}
A New Surgical/ Therapeutic Treatment Model for Spinal cord Injured - Video 2

http://www.youtube.com/watch?v=dfr_XoSQZqY

A New Surgical/ Therapeutic Treatment Model for Spinal cord Injured - Video 3

http://www.youtube.com/watch?v=K7txckEmCM0

A New Surgical/ Therapeutic Treatment Model for Spinal cord Injured - Video 4

http://www.youtube.com/watch?v=HVUAg2TKcSE

A New Surgical/ Therapeutic Treatment Model for Spinal cord Injured - Video 5

http://www.youtube.com/watch?v=v1jhsCdaQI 